\title{
DEMOGRAPHICS AND MAJOR INDICATIONS FOR THE WARFARIN USE, THE COMPLIANCE RATE AND THE FACTORS CONTRIBUTING IN NON-ADHERENCE AMONG PATIENTS PRESENTING TO A TERTIARY CARDIAC CENTER OF PAKISTAN
}

\author{
Muhammad Talha Bin Nazir, Muhammad Mujtaba Ali Siddiqui, Hamid Sharif Khan, Mohsin Saif*, Shabana Kousar, \\ Muhammad Usman Sajid** \\ Rawalpindi Institute of Cardiology, Rawalpindi Pakistan, *Armed Forces Institute of Cardiology/National Institute of Heart Disease \\ (AFIC/NIHD)/National University of Medical Sciences (NUMS) Rawalpindi Pakistan, ${ }^{* * C}$ Combined Military Hospital Jhelum/ National \\ University of Medical Sciences (NUMS) Pakistan
}

\begin{abstract}
Objective: To assess the impact of a dedicated hospital based warfarin clinic assessing patients' knowledge and improving the drug compliance in a tertiary cardiac center of Pakistan.

Study Design: Descriptive cross sectional study.

Place and Duration of Study: Rawalpindi Institute of Cardiology from Jan 2019 to Jul 2019.

Methodology: Patients presenting in the anticoagulation clinic using warfarin for different cardiovascular indications from Jan to Jul 2019 were included in the study. Patients were assessed for their underlying cardiovascular condition, their international normalized ratio levels checked using a standard technique. The patients' knowledge about the drug and the degree of compliance was judged by eight-item Morisky Medication Adherence Scale (MMAS-8). The patients were thoroughly counseled and reassessed six months later assessing the improvement in compliance with the warfarin therapy.

Results: Total number of 401 patients using warfarin for different cardiovascular diseases were studied. The mean age was $43.3 \pm 13.3$ years with $218(54.5 \%)$ patients being male. Most of the patient 300 (75\%) belonged to the low socio-economic group with average monthly income of $<$ PKR $10,000 / \$ 65$. In addition, $61.4 \%$ of the patients belonged to the rural set up. Mechanical valve replacement made the bulk of the indication for warfarin therapy with $44.7 \%$ of patients with mechanical mitral valve, $14 \%$ with mechanical double valve and $13 \%$ with mechanical aortic valve replacement. $13.7 \%$ of the patients on warfarin therapy had atrial fibrillation while $6.9 \%$ either had venous thromboembolism and pulmonary embolism. The compliance was good in $76.1 \%$ on baseline visit which increased to $86.7 \%$ on the first visit at six-month interval. Residence in rural areas and low socioeconomic status were the two factors contributing to poorer compliance which improved on the first visit. Conclusion: Low socioeconomic status and residents of rural areas were resulting in comparatively poorer compliance with warfarin therapy which improved by educating such patients in specific warfarin clinic.
\end{abstract}

Keywords: Compliance, Warfarin therapy, Warfarin clinic.

This is an Open Access article distributed under the terms of the Creative Commons Attribution License (http://creativecommons.org/licenses/by/4.0), which permits unrestricted use, distribution, and reproduction in any medium, provided the original work is properly cited.

\section{INTRODUCTION}

Warfarin has been used in prevention of thromboembolic conditions for decades ${ }^{1}$. It antagonizes the effects of vitamin $\mathrm{K}$ in the lever hence playing its role in prevention of thrombosis and/or embolism². Warfarin is used in various cardiovascular settings associated with high risk of thromboembolism. These include for stroke prophylaxis in atrial fibrillation, for prevention of prosthetic valve thrombosis in patients with prosthetic valves, for DVT prophylaxis in post-

Correspondence: Dr Mohsin Saif, Consultant Cardiologist, AFIC/NIHD Rawalpindi Pakistan operative cases and for the treatment of pulmonary and venous thromboembolism among others $^{3}$.

It is one of those drugs that have a narrow therapeutic index as high levels of warfarin can induce major bleeding complications. International normalized ratio (INR) is tool that is used to assess degree of warfarin effect in the body. The target INR is usually between 2 and 3 but can vary based on the underlying indication ${ }^{4}$. It is measured frequently in the first few weeks after warfarin initiation and subsequently less frequently once the therapeutic range is achieved. 
Maintaining INR within a therapeutic range is important as sub-therapeutic levels of the drugs can lead to thromboembolism and higher than the therapeutic levels can lead to increased major bleeding complication ${ }^{5}$.

Many drugs interact with warfarin; mainly being the antibiotics. Patients' knowledge and education about the drugs regarding the narrow therapeutic index and its interaction with different dugs is vital for the effective and safe use of warfarin. This was illustrated in the Joint Commission International (JCI) National Patient Safety Goal (NPSG) guideline for 2014 which stressed on the education on treatment for patients taking warfarin ${ }^{6}$.

To enhance compliance of warfarin in patients taking the medication, dedicated anticoagulation clinics are set up in different set ups. This usually comprises dedicated primary care physicians and/or pharmacists who with the help of questionnaires, brochures/pamphlets assess patients' knowledge and awareness about the drug, its importance and also guide the patients about the importance of compliance. Studies have shown by establishing and maintaining such clinics improve patients' compliance and reduce complications ${ }^{7}$.

The primary aim of the study was to assess the major indications for the warfarin use, the compliance rate and the reasons contributing into noncomplianceand the impact of warfarin clinic in improving medication compliance in a tertiary cardiac center of Pakistan.

\section{METHODOLOGY}

It is a descriptive cross-sectional study conducted at Rawalpindi Institute of Cardiology. Patients presenting in the anticoagulation clinic using warfarin for different cardiovascular indications from January 2019 to July 2019 were included in the study. Patients were assessed for their underlying cardiovascular condition, their INR levels checked using a standard technique.

Compliance to the medication during each visit was checked using the eight-item Morisky
Medication Adherence Scale (MMAS-8)8, questionnaire. It consists of 8 items, with binary scoring for the first seven items and a 5-point Likert score for the last item. The last item contributes a score between zero and one in 0.25-point increments on a 5-point scale assessing the frequency patients forget take medications (never $=1$, once in a while $=0.75$, sometimes $=0.5$, usually $=0.25$, and all the time $=0$ ). The total score is a summation of all MMAS- 8 items and ranges between 0 and 8 , with scores of 8 reflecting goodcompliance, 7 or 6 reflecting satisfactory compliance, and $<6$ reflecting poor compliance 9 . Based on this the patients' compliance were scored both at the baseline visit and then at three-month visit and compared.

Similarly, counselling was done by a dedicated medical officer performing duties in the warfarin clinic. Each counselling session included the physician, the patient and his next of kin and covering six items of anticoagulation counselling (mode of action of warfarin, adverse effects of over or under anticoagulation, drugs to avoid, action if bleeding or bruising occurs, and alcohol consumption) ${ }^{10}$. At the end of the session the patient was also given a brochure/pamphlet in national language (Urdu) with detailed description about the drug covered in the counselling session. The details of counselling session were documented and signed by both the medical officer and the patient.

\section{Exclusion Criteria}

Patients with co morbid conditions impacting INR levels. The Statistical package for social science SPSS version 24 was used for data analysis. Continuous variables are expressed as mean \pm SD; categorical variables, as frequency with percentages. Student's t-test and chi-square test analysis were carried out for comparison of continuous and categorical variables, respectively. Pair wise $t$ test was used to compare compliance at baseline and first visit at a three month interval and for the factors contributing to compliance at the two visits. A $p$-value $<0.05$ was considered significant. 


\section{RESULTS}

Total of 401 patients using warfarin for different cardiovascular diseases were studied. The mean age was $43.3 \pm 13.3$ years with 218 $(54.5 \%)$ patients being male. The clinical characteristics of these patients on admission are reported in the table-I.

Most of the patient (75\%) belonged to the low socio economic group with average monthly

Table-I: Baseline characteristics of patients.

\begin{tabular}{l|c}
\hline Patient characteristics at diagnosis & $\mathbf{n = 4 0 1}$ \\
\hline $\begin{array}{l}\text { Gender } \\
\text { Female }\end{array}$ & $219(54.6 \%)$ \\
$182(45.4 \%)$ \\
\hline Age & $\begin{array}{c}43.3 \pm 13.3 \\
\text { years }\end{array}$ \\
\hline Locality & $246(61.4 \%)$ \\
Rural & $154(38.6 \%)$ \\
\hline Urban & $16(4.0 \%)$ \\
\hline Diabetes & $20(5.0 \%)$ \\
\hline Hypertension & 2 \\
\hline Alcohol consumption & $16(4.0 \%)$ \\
\hline Ischemic CVA & $6(1.5 \%)$ \\
\hline Labile INR & $5(1.2 \%)$ \\
\hline Pregnancy & \\
\hline $\begin{array}{l}\text { Socioeconomic statue } \\
\text { Low (<PKR 10,000/month) } \\
\text { (<\$65/month) }\end{array}$ & $301(75.0 \%)$ \\
$\begin{array}{l}\text { Middle (PKR10,000-50,000 } \\
\text { /month) (\$65-315/month) }\end{array}$ & $93(23.3 \%)$ \\
$\begin{array}{l}\text { High (>PKR 50,000/month) } \\
\text { (>\$315/month) }\end{array}$ & $7(1.7 \%)$ \\
\hline
\end{tabular}

income of $<$ PKR 10,000./\$65. In addition $61.4 \%$ of the patients belonged to the rural set up. The various cardiovascular conditions requiring warfarin therapy are indicated in table-II.

Mechanical valve replacement made the bulk of the indication for warfarin therapy with $44.7 \%$ of patients with mechanical mitral valve, $14 \%$ with mechanical double valve and $13 \%$ with mechanical aortic valve replacement. $13.7 \%$ of the patients on warfarin therapy had atrial fibrillation while $6.9 \%$ either had venous thromboembolism and pulmonary embolism.

The complications relating to warfarin therapy are tabulated in table III
Compliance to Warfarin therapy was assessed at baseline visit and then at 1st visit. The compliance on the two visits is shown in the table-IV.

As seen here, the compliance was good in $76.1 \%$ on baseline visit which increased to $86.7 \%$

Table-II: Indications of warfarin therapy.

\begin{tabular}{|c|c|c|c|}
\hline \multicolumn{2}{|c|}{ Indication } & \multicolumn{2}{|c|}{$n=401$} \\
\hline \multicolumn{2}{|c|}{ Mechanical MVR } & \multicolumn{2}{|c|}{$180(44.7 \%)$} \\
\hline \multicolumn{2}{|c|}{ Mechanical DVR } & \multicolumn{2}{|c|}{$56(14.0 \%)$} \\
\hline \multicolumn{2}{|c|}{ Mechanical AVR } & \multicolumn{2}{|c|}{$52(13.0 \%)$} \\
\hline \multicolumn{2}{|c|}{ Paroxysmal AF (non valvular) } & & $35(08.7 \%)$ \\
\hline \multicolumn{2}{|c|}{ Valvular AF } & \multicolumn{2}{|c|}{$20(05.0 \%)$} \\
\hline \multicolumn{2}{|c|}{ Bioprosthetic valve } & \multicolumn{2}{|c|}{$22(05.5 \%)$} \\
\hline \multicolumn{2}{|c|}{ VTE } & \multicolumn{2}{|c|}{$13(03.2 \%)$} \\
\hline \multicolumn{2}{|l|}{$\mathrm{PE}$} & \multicolumn{2}{|c|}{$15(03.7 \%)$} \\
\hline \multicolumn{2}{|l|}{ LV clot } & \multicolumn{2}{|c|}{$12(03.1 \%)$} \\
\hline \multicolumn{4}{|c|}{ Table-III: Complications of warfarin therapy. } \\
\hline Compliance & $\begin{array}{c}\text { Baseline } \\
\text { visit }(n=234)\end{array}$ & $\begin{array}{l}\text { First visit } \\
(n=234)\end{array}$ & $\begin{array}{c}p- \\
\text { value }\end{array}$ \\
\hline Good & $178(76.1 \%)$ & $203(86.7 \%)$ & \multirow{3}{*}{0.0042} \\
\hline Satisfactory & $35(14.9 \%)$ & $11(4.7 \%)$ & \\
\hline Poor & $21(8.9 \%)$ & $20(8.5 \%)$ & \\
\hline \multicolumn{4}{|c|}{ Table-IV: Compliance of warfarin in the two visits. } \\
\hline \multicolumn{2}{|c|}{ Complication } & \multicolumn{2}{|c|}{ Frequency $(\%)$} \\
\hline \multicolumn{2}{|c|}{ Minor bleed } & \multicolumn{2}{|c|}{$62(15.5 \%)$} \\
\hline \multicolumn{2}{|l|}{ Major bleed } & \multicolumn{2}{|c|}{$42(10.5 \%)$} \\
\hline \multicolumn{2}{|l|}{ Thrombosis } & \multicolumn{2}{|c|}{$8(2.0 \%)$} \\
\hline \multicolumn{4}{|c|}{ Table-V: Complications of warfarin therapy. } \\
\hline Compliance & $\begin{array}{c}\text { Baseline } \\
\text { visit }(n=234)\end{array}$ & $\begin{array}{c}\text { First visit } \\
(\mathrm{n}=234)\end{array}$ & $\begin{array}{c}p- \\
\text { value }\end{array}$ \\
\hline Good & $178(76.1 \%)$ & $203(86.7 \%)$ & \\
\hline Satisfactory & $35(14.9 \%)$ & $11(4.7 \%)$ & 0.0042 \\
\hline Poor & $21(8.9 \%)$ & $20(8.5 \%)$ & \\
\hline Table-VI: Co & pliance of $w$ & farin in the $t$ & o visits. \\
\hline Complicatio & & Frequency & \\
\hline Minor bleed & & $62(15.5$ & \\
\hline Major bleed & & $42(10.5$ & \\
\hline Thrombosis & & $8(2.0 \%$ & \\
\hline
\end{tabular}

on the first visit at six-month interval. Factors impacting compliance are tabulated in table-V. It should be noted that 145 patients od rural residence and 89 patients of urban residence were seen on follow up. Similarly, 178 patients of low socioeconomic status and 55 patients of middle and high socioeconomic status were seen in the clinic. 
Residence in rural areas and low socioeconomic status were the two factors contributing to poorer compliance which improved on the first visit. regard. One was the patients living in the rural areas had lesser adherence to the treatment compared to those living in the urban areas. Similar results were seen in a study conducted by Wang

Table-VII: Factors influencing warfarin compliance.

\begin{tabular}{l|c|c|c|c}
\hline Factors & $\begin{array}{c}\text { Baseline Compliance } \\
\mathbf{n}(\mathbf{\%})\end{array}$ & $p$-value & $\begin{array}{c}\text { First Visit } \\
\text { Compliance }\end{array}$ & $p$-value \\
\hline Gender & & & & \\
\hline Male & $89(74.7)$ & $>0.999$ & $\begin{array}{c}98(82.3) \\
105(91.3)\end{array}$ & $>0.999$ \\
Female & $89(77.3)$ & & & \\
\hline Locality & $93(64.1)$ & 0.001 & $\begin{array}{c}120(88.8) \\
83(93.2)\end{array}$ & 0.028 \\
\hline $\begin{array}{l}\text { Rural (145 pts seen) } \\
\text { Urban (89 pts seen) }\end{array}$ & $85(96.8)$ & & & \\
\hline Socioeconomic Status & $139(78.1)$ & 0.01 & $\begin{array}{c}153(85.9) \\
47(92.1)\end{array}$ & $>0.999$ \\
\hline Low income (178 pts seen) & $37(88.8)$ & & & \\
Middle/High income (55 pts seen) & &
\end{tabular}

\section{DISCUSSION}

Warfarin, a drug with a narrow therapeutic index is widely used in patients with certain cardiovascular ailments to reduce morbidity and mortality. Strict compliance along with regular monitoring of this drug is needed to avoid any complication both from over and under dosage. Seeing a lot of patients presenting with complications with warfarin, a warfarin clinic was setup at Rawalpindi Institute of Cardiology to see the degree of compliance with this medication; the factors or reasons contributing to poor compliance and the impact of the clinic in improving the compliance of the drug among the common masses.

As seen in the results, the degree of compliance improved from $76.1 \%$ at baseline visit to $86.7 \%$ on the next visit; three months later. Similar results were seen by other studies where introduction of warfarin clinic resulted in an improvement in adherence to the treatment and the subsequent adequate anticoagulation ${ }^{11-13}$. The main reason for the increased compliance was the counselling i.e. educating the patients about the importance of the medication, its side effects and the various complications associated with over and under dosage.

As far as the factors influencing compliance was concerned; two factors stood out in this et al 14 , where $88.6 \%$ of rural patients adhered to the prescribed warfarin dose compared to $97.9 \%$ of those living in the urban areas. The main reason for comparatively poorer adherence was lack of education ${ }^{15,16}$, low socioeconomic status and difficulty in commuting to the hospital/ pharmacy shop in getting/purchasing the medicine. Importantly the degree of drug adherence improved among these rural patients at three months visit which further illustrates the importance of establishing warfarin clinic and subsequent patient education. Similarly, socioeconomic status impacted patient comp-liance with the medication; seen more in those with middle and high socioeconomic class patients. Schaefer et al17, also found low socio-economic status as a factor in maintaining comp-liance with warfarin and early switching to other drugs. Similar results were seen in a study conducted by Zhao et al18, who found that patients with lower socioeconomic status had poorer compliance and adherence with warfarin therapy. The reason was again the lower education level, residence in rural areas which were usually far from the hospitals/ pharmacy.

\section{CONCLUSION}

In Pakistan; a developing country with under developed health care system we concluded that low socioeconomic status and residence in rural areas were two factors resulting in 
comparatively poorer compliance with warfarin therapy which improved by educating such patients in specific warfarin clinic. This also necessitates the need for establishing more such dedicated anticoagulation/warfarin clinics especially in the tertiary care centers of the country.

\section{CONFLICT OF INTEREST}

This study has no conflict of interest to be declared by any author.

\section{REFERENCES}

1. Tait RC. Anticoagulation in patients with thromboembolic disease. Thorax 2001; 56(Suppl-II): 30-37.

2. Ufer $M$. Comparative pharmacokinetics of vitamin $K$ antagonists: warfarin, phenprocoumon and acenocoumarol. Clin Pharmacokinet 2005; 44(12): 1227-46.

3. Tadros R, Shakib S. Warfarin--indications, risks and drug interactions. Aust Fam Phys 2010; 39(7): 476-79.

4. Hirsh J, Fuster V, Ansell J, Halperin JL. American Heart Association, American College of Cardiology Foundation. American Heart Association;American College of Cardiology Foundation, American Heart Association/American College of Cardiology Foundation Guide to warfarin therapy. Circulation 2003; 107(12): 1692-11.

5. Lane DA. Maintaining therapeutic anticoagulation: the importance of keeping "within range" Chest 2007; 131(5): 1277-79.

6. Joint Commission International National Patient Safety Goal Guideline. 2014

7. Mckenzie JA, Wilson-Clarke C, Prout J, Campbell J, Douglas RD, Gossell-Williams M. Improving warfarin therapy through implementation of a hospital-based pharmacist managed clinic in Jamaica. Pharm Pract (Granada) 2018; 16(4): 1214-18.

8. Al Ghurair SA, Hughes CA, Simpson SH, Guirguis LM. A systematic review of patient self-reported barriers of adherence to antihypertensive medications using the world health. Organization multidimensional adherence model. J Clif Hypertens (Greenwich) 2012; 14(12): 877-86.

9. Taylor FC, Ramsay ME, Tan G, Gabbay J, Cohen H. Evaluation of patients' knowledge about anticoagulant treatment. Qual Health Care 1994; 3(2): 79-85.

10. Tan CSL, Teng GG, Chong KJ, Cheung PP, Lim AYN, Wee HL, et al. Utility of the Morisky Medication Adherence Scale in gout: a prospective study. Patient Prefer Adherenc 2016; 10(1): 2449-57.

11. Mason BJ. Anticoagulant Clinic Warfarin Adherence Rates and Assessment. Journal of Pharmacy Technology, 1996; 12(3): 97-01.

12. Rossiter J, Soor G, Telner D, Aliarzadeh B, Lake J. A PharmacistLed Point-of-Care INR Clinic: Optimizing Care in a Family Health Team Setting. Int J Family Med 2013; 2013(1): 691454.

13. Aidit S, Soh YC, Yap CS, Khan TM, Neoh CF, Shaharuddin S, et al. Frontiers in Pharmacol 2017; 8(1): 637.

14. Wang X, Xu B, Liang H, Jiang S, Tan H, Wang X, et al. Distribution characteristics and factors influencing oral warfarin adherence in patients after heart valve replacement. Patient Prefer Adherenc 2018; 12(1): 1641-48.

15. Khan AR, Lateef ZNA-A, Al Aithan MA, Bu-Khamseen MA, Al Ibrahim I, Khan SA. Factors contributing to non-compliance among diabetics attending primary health centers in the Al Hasa district of Saudi Arabia. J Family Community Med 2012; 19(1): 26-28.

16. Al-Saikhan FI, Abd-Elaziz MA, Ashour RH, Langaee T. Anticoagulation Therapy: For Patients Attitude, Knowledge and Concerns Regarding their Effects on International Normalized Ratios in Saudi Arabia. Inter J Pharmacol 2018; 14(2): 285-90.

17. Schaefer JK, Sood SL, Haymart B, Gu X, Kong X, Kline-Rogers E et al. Sociodemographic factors in patients continuing warfarin vs those transitioning to direct oral anticoagulants. Blood Adv 2017; 1(26): 2536-40.

18. Zhao S, Zhao H, Wang X, Gao C, Qin y, Cai H, et al. Factors influencing medication knowledge and beliefs on warfarin adherence among patients with atrial fibrillation in China. Patient Prefer Adherenc 2017; 11(1): 213-20. 